\title{
Serum Level of Cytokeratin-18/M30 Antigen is Increased in the Cases with Impaired Glucose Tolerance
}

\author{
Solen Himmetoglu', Selin Yuksel ${ }^{2}$, Taner Damcl ${ }^{3}$, Hasan Ilkova ${ }^{3}$ and Yildiz Dincer ${ }^{2 *}$ \\ ${ }^{1}$ Department of Medical Biochemistry, T.C. Biruni University Medical Faculty, Turkey \\ ${ }^{2}$ Department of Medical Biochemistry, Istanbul University, Turkey \\ ${ }^{3}$ Department of Endocrinology, Istanbul University, Turkey
}

*Corresponding author: Yildiz Dincer, Department of Medical Biochemistry, Istanbul University, Cerrahpasa Medical Faculty, Dere Sok. Umut Ap. No: 11/44 Sahrayicedit, Erenkoy, Istanbul, Turkey, Tel: 90-212-4143000/23004, E-mail: yldz.dincer@gmail.com

\begin{abstract}
Background: Beta cell death by apoptosis is an important mechanism in beta cell dysfunction and development of diabetes. Inhibition of apoptosis may be helpful approach in the prevention of diabetes. In this context, non-invasive, specific markers are needed to detect apoptosis in prediabetic stage. In the present study serum levels of cytokeratin-18/M30 antigen, a surrogate marker of apoptosis were investigated in cases with type 2 diabetes and Impaired Glucose Tolerance (IGT).

Materials and methods: A total of 44 patients with type 2 diabetes, 27 cases with IGT, and 27 control cases were involved in the study. Serum levels of cytokeratin-18/M30 antigen were determined by ELISA kit in the blood samples taken after an overnight fast.

Results: Serum level of cytokeratin-18/M30 antigen was found to be higher in the IGT group than those in the control group $(P<0.05)$. Serum level of cytokeratin-18/M30 antigen was also higher in the type 2 diabetes group in comparison to those in the control group, but this increase was not statistically significant. In the type 2 diabetes group, a positive correlation was determined between cytokeratin-18/M30 antigen and fasting glucose ( $r$ : 0.430; $P<0.005)$; cytokeratin-18/M30 antigen level was negatively correlated with ratio of c-peptide/fasting glucose ( $r$ : $-0.506 ; \mathrm{P}<0.05)$.

Conclusion: Serum cytokeratin-18/M30 antigen level is increased in the cases with IGT. This would imply that it may be a useful marker in the detection of apoptosis in prediabetic stage. However, the origin of increased cytokeratin-18/M30 antigen is not clear. This increase may also reflect apoptosis of inflamed fatty liver cells that is linked the pathogenesis of type 2 diabetes.
\end{abstract}

\section{Keywords}

Type 2 diabetes, Impaired glucose tolerance, Apoptosis, Cytokeratin-18/ M30 antigen

\section{Introduction}

Insulin resistance is an early event in development of type 2 diabetes. In order to balance insulin resistance, pancreatic $\beta$-cells enhance production and secretion of insulin. Chronic hyperglycemia and prolonged temporary postprandial hyperglycemia causes further deterioration in $\beta$-cell function [1]. Apoptosis, programmed cell death, is a normal process that occurs during morphogenesis, but it also contributes to some pathological processes. Pancreatic beta cells can undergo apoptosis in vivo. Beta cell death by apoptosis was clearly demonstrated by Scaglia, et al. in 1995 for the first time [2]. Over time, investigations revealed the mechanisms involved in $\beta$-cell apoptosis and responsible stimuli in this event [3-5].

Apoptotic cell death occurs via extrinsic and intrinsic pathways. Extrinsic pathway is initiated by binding of death ligands to cell surface receptors. The intrinsic pathway is activated by DNA damage, and results in cytochrome $c$ release from mitochondria. Activation of both pathways results in a downstream activation of a group of proteases, called as procaspases, in the cytoplasm. Activated caspases lead to activation of endonucleases, which in turn causes DNA fragmentation

Citation: Himmetoglu S, Yuksel S, Damcı T, Ilkova H, Dincer Y (2017) Serum Level of Cytokeratin-18/ M30 Antigen is Increased in the Cases with Impaired Glucose Tolerance. Int Arch Endocrinol Clin Res 3:011. doi.org/10.23937/2572-407X.1510011

Received: September 18, 2017: Accepted: November 20, 2017: Published: November 22, 2017

Copyright: (c) 2017 Himmetoglu S, et al. This is an open-access article distributed under the terms of the Creative Commons Attribution License, which permits unrestricted use, distribution, and reproduction in any medium, provided the original author and source are credited. 
[6]. Cytokeratin 18 is a cytoskeleton protein of epithelial cells. M30 antigen is a fragment of cytokeratin 18 which forms during apoptotic cell death, and is released into circulation. Cytokeratin-18/M30 antigen level in serum is a surrogate marker for apoptosis $[7,8]$, and is determined as a marker of Nonalcoholic Steatohepatitis (NASH) in many studies [9-11].

Hyperglycaemia is suggested to induce apoptosis via p53 pathway [3]. p53 is a transcription factor which is activated in response to DNA damage. It stimulates expression of genes which are involved in cell cycle arrest at the G1/S transition to direct cell either DNA repair or apoptosis. In our previous study, we examined serum levels of p53 and cytochrome c, as markers of apoptosis in the patients with type 2 diabetes and cases with Impaired Glucose Tolerance (IGT) [12]. We determined lower serum P53 level in the patients with type 2 diabetes in comparison to control and IGT cases but there was no significant difference for serum cytochrome $c$ level betwen the groups. We concluded that p53 and cytochrome $\mathrm{c}$ are not good markers to reflect the apoptosis of beta cells in peripheral circulation. The present study was designed as a continuation of our previous investigation. It was purposed to examine serum levels of cytokeratin-18/M30 antigen in the cases with type 2 diabetes and IGT.

\section{Materials and Methods}

A total of 44 patients with type 2 diabetes ( 21 men and 23 women) and 27 cases with IGT ( 11 men and 16 women) were enrolled from the Endocrinology, Metabolism and Diabetes Department of Cerrahpasa Medical Faculty Hospital. Type 2 diabetes was diagnosed based on common clinical and laboratory findings. The mean duration of disease was $8 \pm 2 \mathrm{yr}$. Thirty two of the subjects were being treated with oral anti-diabetic agents. 21 subjects were taking metformin, and 11 subjects were taking metformin + gliclazide. Fourteen subjects with type 2 diabetes have at least one complication such as retinopathy, neuropathy, nephropathy or angiopathy. Other patients were free from diabetic complications. Oral Glucose Tolerance test was applied to subjects who have a fasting glucose concentration between $110-126 \mathrm{mg} / \mathrm{dl}$. Briefly $75 \mathrm{~g}$ of glucose dissolved in $200 \mathrm{~mL}$ tap water was given orally in the morning (7 am). Blood samples were taken just before $(0 \mathrm{~min})$ and 30,90 , and 120 min after glucose application for analyses of serum glucose concentration. These time points were chosen to cover a 2-hour period. The IGT group was constituted by cases who have a glucose concentration between $140-200 \mathrm{mg} / \mathrm{dl}$ at the second hour of Oral Glucose Tolerance Test. Cases with IGT were not receiving any medication. They had normal liver, thyroid and renal function. Three of the cases were smoker ( 1 cigarette/day). The control group was constituted by age and sex-matched 27 healthy volunteers ( 12 men and 15 women) among staff of the Cerrahpasa Medical
Faculty. None of the controls had a family history of diabetes, and they had normal glucose tolerance. Cases with cancer, autoimmune disease, acute and/or chronic inflammatory disease, thyroid disorder, and cases who were taking alcohol and smoking more than 1 cigaret/ day were excluded from the study.

\section{Blood sampling and measurements of cytokera- tin-18/M30 antigen}

$5 \mathrm{ml}$ of venous blood samples were taken from all cases after an overnight fast. Blood sample was centrifugated at $3000 \mathrm{Xg}$ for $10 \mathrm{~min}$, serum was removed and kept at the $-80^{\circ} \mathrm{C}$ until analysis. Serum level of cytokeratin-18/M30 antigen was determined by ELISA kit from Peviva AB (catolog no: 10010, Bromma, Sweden). Measurements were performed according to manufacturers instructions. Serum levels of glucose and c-peptide were measured in the routine analysis laboratory by spectrophotometric and chemiluminescent methods, respectively. Glycosylated Hemoglobin (HbA1c) levels in erythorcytes were determined by HPLC in the same laboratory.

\section{Statistical analysis}

Data are expressed as median and min-max. Statistical analysis was performed by SPSS software (version 15). Abnormally distributed data were analysed by nonparametric Kruskal Wallis test. Comparison of two groups was performed by Mann Whitney U test. A value of $P<0.05$ was considered as significant. Correlation analysis was performed by Spearman correlation coefficient.

\section{Results}

Characteristics of the study groups and serum cytokeratin-18/M30 antigen levels are shown in the Table 1. Serum level of cytokeratin-18/M30 antigen was significantly higher in the IGT group than those in the control group $(P<0.05)$. Serum level of cytokeratin-18/ M30 antigen was also higher in the type 2 diabetes group in comparison to those in control group but this increase was not statistically significant (Table 1). In the type 2 diabetes group, patients who have a HbA1c level higher than 6.5 were considered poorly controlled diabetics. There was no significant difference between controlled and poorly controlled diabetic patients and between patients with and without diabetic complications for cytokeratin-18/M30 antigen level. Treatment with oral anti-diabetic agents was not found to be related with serum cytokeratin-18/M30 antigen level. A positive correlation between cytokeratin-18/M30 antigen and fasting glucose ( $r$ : 0.430; $P<0.005)$; a negative correlation between cytokeratin-18/M30 antigen and c-peptide/fasting glucose ratio $(r:-0.506 ; \mathrm{P}<0.05)$ were determined in the type 2 diabetes group. No significant correlation was found between cytokeratin-18/M30 antigen and Body Mass Index (BMI). There was no sig- 
Table 1: Characteristics of the study groups and serum cytokeratin-18/M30 antigen levels.

\begin{tabular}{|l|l|l|l|}
\hline & $\begin{array}{l}\text { Control Group } \\
(\mathrm{n}=27)\end{array}$ & $\begin{array}{l}\text { IGT Group } \\
(\mathrm{n}=27)\end{array}$ & $\begin{array}{l}\text { Type 2 Diabetes Group } \\
(\mathrm{n}=44)\end{array}$ \\
\hline Age (year) & $53(35-66)$ & $50(19-77)$ & $56(37-74)$ \\
\hline BMI (kg/m $\left.{ }^{2}\right)$ & $28(24-32)$ & $30(24-48)$ & $29(17-42)$ \\
\hline Sistolic Pressure (mm/Hg) & $12(9-14)$ & $12(9-16)$ & $13(11-20)$ \\
\hline Diastolic Pressure (mm/Hg) & $7(5-9)$ & $8(5-9)$ & $8(6-10)$ \\
\hline Total Cholesterol (mg/dL) & $180(98-200)$ & $192(100-259)$ & $177(104-266)$ \\
\hline Triglyceride (mg/dL) & $115(34-201)$ & $121(43-312)$ & $112(21-228)$ \\
\hline HDL (mg/dL) & $49(36-73)$ & $45(33-64)$ & $47(32-71)$ \\
\hline LDL (mg/dL) & $115(48-153)$ & $115(44-162)$ & $111(53-201)$ \\
\hline Fasting glucose (mg/dL) & $88(71-101)^{a}$ & $100(86-124)^{b}$ & $111(84-195)$ \\
\hline c-Peptide (ng/mL) & $3.38(1.20-8.40)^{c}$ & $3.30(0.81-8.64)$ & $3.21(1.41-6.20)$ \\
\hline HbA1c (\%) & $5.3(4.8-5.9)^{\mathrm{a}}$ & $6.0(4.8-6.9)^{\mathrm{d}}$ & $6.4(5.5-9.0)$ \\
\hline Cytokeratin-18/M30 antigen (U/L) & $135(10-510)$ & $182(75-950)^{\mathrm{e}}$ & $170(10-1000)$ \\
\hline
\end{tabular}

aP $<0.001$ versus Type 2 Diabetes Group and IGT Group, ${ }^{b} \mathrm{P}<0.005$ versus Type 2 Diabetes Group, ${ }^{\mathrm{c} P}<0.05$ versus Type 2 Diabetes Group, ${ }^{d P}<0.01$ versus Type 2 Diabetes Group, ${ }^{e} P<0.05$ versus Control Group.

nificant relationship between cytokeratin-18/M30 antigen level and levels of insulin and glucose in the control group.

\section{Discussion}

Adequate amount of insulin secretion from pancreas depends on both functional integrity and mass of the $\beta$-cells. Apoptosis is an important mechanism in pancreatic beta-cell death and development of not only type 1 but also type 2 diabetes [1]. It has been suggested that hyperglycemia induces apoptosis without any compensatory increase in $\beta$-cell proliferation, and leads a decrease in $\beta$-cell mass [13-16]. Loss of $\beta$-cell mass in diabetes is exacerbated by islet amyloid deposits and oxidative stress. $\beta$-cell apoptosis is determined in human pancreatic sections and postmortem islet grafts in correlation with amount of amyloid deposits [17,18]. Oxidative stress is a contributory mechanism in beta cell apoptosis. It is well documented that production of Reactive Oxygen Species (ROS) is increased in beta cells, which in turn stimulates apoptosis [19-21].

Taken together, all previous data demonstrate pivotal role of apoptosis in beta cell dysfunction and development of diabetes. Since apoptosis is a contributory mechanism in pathogenesis of diabetes mellitus, blocking of apoptosis may be a new therapeutic approach in the prevention of diabetes. Non-invasive, specific markers are needed to detect apoptosis. In the present study, serum cytokeratin-18/M30 antigen was examined as a new marker to assess apoptosis in cases with IGT and type 2 diabetes. As far as we know, there is no clinical research examining serum levels of cytokeratin-18/M30 antigen neither in prediabetic stage nor in diabetes. In general, serum cytokeratin-18/M30 antigen level has been measured as a marker of apoptosis in patients with cancer [22-25], chronic hepatitis B or C virus infection [26,27], non-alcoholic liver disease [7,9-11,28] idiopathic interstitial pneumonia [29], and morbid obesity [30]. The present study is first to demonstrate increased cytokeratin-18/M30 antigen level in patients with type 2 diabetes and cases with IGT. Actually, serum cytokeratin-18/M30 antigen level was also higher in the type 2 diabetes group in comparison to control group but this difference did not reach at a significant level. As a limitation of the present study, the number of study cases was small. Cytokeratin-18/M30 antigen measurements in larger study groups may reveal a significant difference between patients with type 2 diabetes and healthy controls. In agreement with this suggestion, the positive correlation determined between cytokeratin-18/M30 antigen and fasting glucose in the type 2 diabetes group ( $r: 0.430 ; P<0.005$ ), and the negative correlation found between cytokeratin-18/M30 antigen and c-peptide/fasting glucose ratio ( $r$ : $-0.506 ; \mathrm{P}<0.05)$ indicate the probable association of apoptosis and type 2 diabetes. In addition, increased cytokeratin-18/M30 antigen level determined in the IGT group may be an evidence for apoptosis in pre-diabetes stage.

On the other hand, diabetes and IGT are associated with increased amount of liver fat content and visceral fat mass [31]. Recently, majority of the data about cytokeratin-18/M30 antigen levels are derived from studies which determine whether CK18 serum level may serve as a marker for Nonalcoholic Fatty Liver Disease (NAFLD) or NASH [9-11]. Cytokeratin-18/M30 antigen serum level has been found to be a promising non-invasive biomarker for NASH in children with fatty liver disease [11], as well in adults with NAFLD [9], and cytokeratin-18/M30 antigen testing has been suggested as a useful tool in clinical practice. On the basis of these data, the higher cytokeratin-18/M30 antigen levels in the IGT group determined in the present study may represent a higher liver fat content, more realistically higher prevalence of inflamed fatty liver in these individuals. The liver is involved in the pathogenesis of type 2 diabetes. Especially, the liver is responsible for increased glucose production and dysregulated lipoprotein metabolism, conditions that are often found in patients with NAFLD. Additionally, several proteins that are exclusively or predominantly secreted from the liver are now known 
to directly affect glucose and lipid metabolism [32]. For instance, fetuin-A is a glycoprotein synthesized in liver. It is a negative regulator of insulin action with its inhibitory effect on insulin receptor tyrosine kinase. Fetuin-A-fatty acid complex induces inflammatory signaling and insulin resistance that are involved in pathogenesis of type 2 diabetes mellitus [33]. Given these data, we think that increased cytokeratin-18/M30 antigen level in the subjects with IGT may reflect the increased apoptosis of liver cells. Unfortunately, as a limitation of this study, serum ALT, AST and GGT levels that are the markers of liver function were not measured.

\section{Conclusion}

In the present study we determined increased serum cytokeratin-18/M30 antigen level in the cases with IGT. It is not clear whether increased cytokeratin-18/M30 antigen originated from pancreatic beta cells or not. This increase may also reflect higher prevalence of inflamed fatty liver that is linked the pathogenesis of type 2 diabetes. In order to clarify exact origin of circulating cytokeratin-18/M30 antigen in both prediabetic and diabetic states further investigations are needed.

\section{Acknowledgements}

This work was supported by the Research Fund of Istanbul University (Project no: BYP-7209 and UDP-35836).

\section{Conflict of Interest}

None of the authors have a conflict of interest. Cerrahpasa Medical Faculty Ethics Committee approval was taken in accordance with the principles of the Declaration of Helsinki and informed consent was obtained from all cases.

\section{References}

1. Sesti G (2002) Apoptosis in the beta cells: Cause or consequence of insulin secretion defect in diabetes? Ann Med 34: 444-450.

2. Scaglia L, Smith FE, Bonner-Weir S (1995) Apoptosis contributes to the involution of beta cell mass in the post partum rat pancreas. Endocrinology 136: 5461-5468.

3. Adeghate E (2004) Molecular and cellular basis of the aetiology and management of diabetic cardiomyopathy: a short review. Mol Cell Biochem 261: 187-191.

4. Butler AE, Janson J, Bonner-Weir S, Ritzel R, Rizza RA, et al. (2003) Beta-cell deficit and increased beta-cell apoptosis in humans with type 2 diabetes. Diabetes 52: 102-110.

5. Maris M, Robert S, Waelkens E, Derua R, Hernangomez $\mathrm{MH}$, et al. (2013) Role of the saturated nonesterified fatty acid palmitate in beta cell dysfunction. J Proteome Res 12 347-362.

6. Vaux DL, Strasser A (1996) The molecular biology of apoptosis. Proc Natl Acad Sci U S A 93: 2239-2244.

7. Lavallard VJ, Bonnafous S, Patouraux S, Saint-Paul MC Rousseau D, et al. (2011) Serum markers of hepatocyte death and apoptosis are non invasive biomarkers of severe fibrosis in patients with alcoholic liver disease. PLoS One 6: e17599.
8. Cha SI, Ryerson CJ, Lee JS, Kukreja J, Barry SS, et al. (2012) Cleaved cytokeratin-18 is a mechanistically informative biomarker in idiopathic pulmonary fibrosis. Respir Res 13: 105.

9. Feldstein AE, Wieckowska A, Lopez AR, Liu YC, Zein NN, et al. (2009) Cytokeratin-18 fragment levels as noninvasive biomarkers for nonalcoholic steatohepatitis: a multicenter validation study. Hepatology 50: 1072-1078.

10. Santoro N, Feldstein AE, Enoksson E, Pierpont B, Kursawe $R$, et al. (2013) The association between hepatic fat content and liver injury in obese children and adolescents: effects of ethnicity, insulin resistance, and common gene variants. Diabetes Care 36: 1353-1360.

11. Feldstein AE, Alkhouri N, De Vito R, Alisi A, Lopez R, et al. (2013) Serum cytokeratin-18 fragment levels are useful biomarkers for nonalcoholic steatohepatitis in children. Am J Gastroenterol 108: 1526-1531.

12. Dincer $Y$, Himmetoglu S, Yalin S, Damci T, Ilkova $H$, et al. (2009) Serum levels of p53 and cytochrome c in subjects with type 2 diabetes and impaired glucose tolerance. Clin Invest Med 32: E266-E270.

13. Maedler K, Donath MY (2004) Beta-cells in type 2 diabetes: A loss of function and mass. Horm Res 62: 67-73.

14. Ahrén B (2005) Type 2 diabetes, insulin secretion and beta-cell mass. Curr Mol Med 5: 275-286.

15. Pearl-Yafe M, Kaminitz A, Yolcu ES, Yaniv I, Stein J, et al. (2007) Pancreatic islets under attack: cellular and molecular effectors. Curr Pharm Des 13: 749-760.

16. Lai X, Kang X, Zeng L, Li J, Yang Y, et al. (2014) The protective effects and genetic pathways of thorn grape seeds oil against high glucose-induced apoptosis in pancreatic ß-cells. BMC Complement Altern Med 14: 10.

17. Montane J, Klimek-Abercrombie A, Potter KJ, Westwell-Roper C, Bruce Verchere C (2012) Metabolic stress, IAPP and islet amyloid. Diabetes Obes Metab 14: 68-77.

18. Andersson A, Bohman S, Borg LA, Paulsson JF, Schultz SW, et al. (2008) Amyloid deposition in transplanted human pancreatic islets: a conceivable cause of their long-term failure. Exp Diabetes Res 2008: 562985.

19. Lenzen S (2008) Oxidative stress: The vulnerable beta-cell. Biochem Soc Trans 36: 343-347.

20. Houstis N, Rosen ED, Lander ES (2006) Reactive oxygen species have a causal role in multiple forms of insulin resistance. Nature 440: 944-948.

21. Robertson RP, Harmon JS (2007) Pancreatic islet beta-cell and oxidative stress: The importance of glutathione peroxidase. FEBS Lett 581: 3743-3748.

22. Ulukaya E, Karaagac E, Ari F, Oral AY, Adim SB, et al. (2011) Chemotherapy increases caspase cleaved cytokeratin 18 in the serum of breast cancer patients. Radiol Oncol 45: 116-122.

23. Yaman E, Coskun U, Sancak B, Buyukberber S, Ozturk B, et al. (2010) Serum M30 levels are associated with survival in advanced gastric carcinoma patients. Int Immunopharmacol 10: 719-722.

24. Tas F, Karabulut S, Bilgin E, Sen F, Yildiz I, et al. (2013) Clinical significance of serum M30 and M65 levels in metastatic pancreatic adenocarcinoma. Tumour Biol 34: 3529-3536.

25. Oyama K, Fushida S, Kinoshita J, Okamoto K, Makino I, et al. (2013) Serum cytokeratin 18 as a biomarker for gastric cancer. Clin Exp Med 13: 289-295. 
26. Bae CB, Kim SS, Ahn SJ, Cho HJ, Kim SR, et al. (2013) Caspase-cleaved fragments of cytokeratin-18 as a marker of inflammatory activity in chronic hepatitis $B$ virus infection. $\mathrm{J}$ Clin Virol 58: 641-646.

27. Kronenberger B, Wagner M, Herrmann E, Mihm U, Piiper A, et al. (2005) Apoptotic cytokeratin 18 neoepitopes in serum of patients with chronic hepatitis C. J Viral Hepat 12: 307-314.

28. Kim YS, Jung ES, Hur W, Bae SH, Choi JY, et al. (2013) Noninvasive predictors of nonalcoholic steatohepatitis in Korean patients with histologically proven nonalcoholic fatty liver disease. Clin Mol Hepatol 19: 120-130.

29. Chung WY, Sun JS, Park JH, Lee HL, Lee KS, et al. (2010) Epithelial apoptosis as a clinical marker in idiopathic interstitial pneumonia. Respir Med 104: 1722-1728.
30. Civera M, Urios A, Garcia-Torres ML, Ortega J, Martinez-Valls $\mathrm{J}$, et al. (2010) Relationship between insulin resistance, inflammation and liver cell apoptosis in patients with severe obesity. Diabetes Metab Res Rev 26: 187-192.

31. Kantartzis K, Machann J, Schick F, Fritsche A, Häring HU, et al. (2010) The impact of liver fat vs visceral fat in determining categories of prediabetes. Diabetologia 53: 882-889.

32. Stefan N, Haring HU (2013) The role of hepatokines in metabolism. Nat Rev Endocrinol 9: 144-152.

33. Stefan N, Haring HU (2013) Circulating fetuin-A and free fatty acids interact to predict insulin resistance in humans. Nat Med 19: 394-395. 